\title{
LOS PROYECTOS EDUCATIVOS DEL SIGLO XIX: MÉXICO Y LA CONSTRUCCIÓN DE LA NACIÓN Rosalía Meníndez*
}

RESUMEN: Durante el siglo XIX se ensayan diversos proyectos educativos, tanto conservadores como liberales. Sólo hasta la llegada de Porfirio Díaz al poder consigue uno de estos proyectos volverse realidad.

PALABRAS ClAVE: educación, siglo XIX, México, Juárez, Díaz.
ABSTRACT: In the nineteenth century, several conservative and liberal educational projects were tried out, however it was until Porfirio Diaz's rise to power that one became a reality.

KEYWORDS: education, nineteenth century, Mexico, 


\section{LOS PROYECTOS EDUCATIVOS DEL SIGLO XIX: MÉXICO Y LA CONSTRUCCIÓN DE LA NACIÓN}

\section{Introducción}

La política educativa que hoy día se aplica en los diferentes espacios y ámbitos educativos del país resulta impensable si desconocemos o ignoramos su pasado histórico, es decir, su memoria; el presente artículo tiene por objeto presentar algunas ideas, planteamientos y propuestas que dieron origen a la construcción de proyectos educativos a lo largo del siglo XIX; a partir de este material se analiza la destacada labor de profesores, pedagogos, políticos y educadores interesados en la educación del país.

El siglo XIX resulta de gran importancia y yo diría que es fundamental para comprender la construcción de un sistema educativo moderno organizado y dirigido por el Estado. De allí la pertinencia de hablar de los orígenes de la política educativa contemporánea.

\section{Iniciativas y ensayos educativos: la construcción de la nación mexicana, 1821-1854}

El año de 1821 marca el inicio de la vida independiente del país; el momento resulta complejo y difícil pues es necesario imaginar a la nación y dar paso a su construcción; las propuestas son variadas pues son el reflejo de los actores políticos involucrados en el moviendo independen- 
tista; borbonistas, iturbidistas, insurgentes y liberales, cada unos de estos grupos con diferentes visiones culturales e ideológicas; sin embargo, existe un punto que los une e identifica, el educativo; las declaraciones gubernamentales de la época ilustran el punto: "Nada puede contribuir tanto a la prosperidad nacional, como la ilustración pública y la acertada dirección que se dé a la juventud", declara en 1823 el Supremo Poder Ejecutivo de la joven República. ${ }^{1}$ Más tarde, Guadalupe Victoria declara: "La ilustración sirve para la existencia de las naciones, las educa y las conserva". Bajo esta misma línea, Vicente Guerrero declara: "Convencido de que las luces preparan y hacen triunfar el imperio de las libertades, abriré todas las fuentes de la instrucción pública. Los gobiernos populares, para quienes es un interés que los pueblos no vivan humillados, se apresuran a dar a las artes y las ciencias el impulso que tanto les conviene". ${ }^{2}$ Podemos ver que este interés se vincula con la necesidad de impulsar el progreso, la libertad y la razón en la joven nación, pero esto no será suficiente: habrá que impulsar acciones más concretas.

Ya el gobierno de Agustín de Iturbide, en 1822, intenta considerar el tema educativo; sin embargo, care-

${ }^{1}$ François Xavier Guerra, México del antiguo régimen a la revolución, 1995, México, FCE, p. 394. ${ }^{2}$ Ibid. ce de fondos suficientes para apoyar un proyecto amplio, por tanto, éste queda en manos de la Compañía Lancasteriana, ${ }^{3}$ la cual debía fundar con el tiempo escuelas elementales y normales; el Estado quiere impulsar la educación, pero no cuenta con los recursos necesarios; por ello, deberá valerse de instituciones alternas que apoyen esta iniciativa.

El primer ensayo educativo se presenta en el año de 1823 bajo el gobierno del Supremo Poder Ejecutivo, Proyecto de Reglamento General de Instrucción Pública; en su art. $1^{\circ}$ se anota que la educación ha de ser pública y gratuita. $\mathrm{El}$ art. $3^{\circ}$, todo ciudadano tiene derecho a instruirse; nadie ha de pagar por ella, y la instrucción será uniforme y por los mismos métodos y tratados elementales. Art. $6^{\circ}$, se suprimen los gremios de maestros, pues todo ciudadano tiene facultades de formar establecimientos de instrucción. Arts. $11^{\circ}$ y $12^{\circ}$, la Instrucción Pública estará a cargo de una Dirección Nacional. Art. 33, prescribe que se establezcan escuelas públicas de primeras letras para instruir a los niños y formar sus costum-

${ }^{3}$ La Compañía Lancasteriana fue fundada en el año de 1822; los fundadores fueron: doctor Manuel Codorniú, licenciado Agustín Buen Rostro, Manuel Fernández Aguado, coronel Eulogio Villaurrutia y profesor Nicolás Germán Prissete, sustituido éste más tarde por el profesor Eduardo Turreau de Linieres. La primera escuela de la Compañía fue ubicada en el local de la Antigua Sala Secreta de la Inquisición. 
bres en utilidad propia y provecho de la nación. ${ }^{4}$ Así mismo, se establece un currículo para la primaria; en éste, se presentan las asignaturas de lectura, escritura, aritmética, geometría, gramática, catecismo religioso y moral, dibujo y dos materias fundamentales para el nuevo Estado: Constitución del Estado y Catecismo Político, es decir, se da un espacio al tema cívico y por tanto a la formación (si bien incipiente) de ciudadanos.

Este proyecto consideró la educación de las niñas y de los adultos y se ordenó la creación de escuelas para atenderlos.

La educación de primeras letras fue la prioridad del gobierno, es decir, la que atendía la enseñanza de la escritura y la lectura fundamentalmente, aunque también se dio atención a la educación superior; las carreras establecidas fueron: teología, jurisprudencia canónica y civil, medicina, cirugía $\mathrm{y}$ farmacia y ciencias naturales.

Las buenas intenciones de Pedro Celestino Negrete, Nicolás Bravo y Guadalupe Victoria fueron eso: un excelente propósito que no se llevó a cabo; la razón fue la falta de recursos económicos, maestros y espacios escolares.

A los pocos meses se instauró la República Federal y se promulgó una

${ }^{4}$ Ver Ernesto Meneses, Tendencias educativas oficiales en México, 1821-1911, 1998, México, Centro de Estudios Educativos y Universidad Iberoamericana, p. 94. nueva constitución política y un nuevo plan educativo que se dio a conocer en 1826.

Fue la segunda propuesta educativa; nuevamente encontramos la insistencia de que la instrucción pública se dé en establecimientos destinados para tal efecto; se presentó un currículo para primaria, que incluía prácticamente las mismas asignaturas que el anterior, aunque destacan la inclusión de las materias de moral y urbanidad; además, se incluye una nueva materia: "Conocimientos de Derechos Civiles". Se continúa con el tema cívico, tan necesario para una nación en ciernes. La instrucción es obligatoria y se llevará según el método lancasteriano. En el Distrito Federal son los ayuntamientos los encargados de impartir esta educación: por cada pueblo de 100 familias deberá establecerse una escuela; los maestros serán seleccionados según lo acordado por el ayuntamiento; las plazas de instrucción se otorgarán por examen público ante un comité elegido por esta instancia y éste se validará cada dos años.

Respecto de la escuela preparatoria, ésta enriquece su currículo con materias un tanto científicas, como mineralogía, geología, botánica, zoología e incluye gramática de lenguas antiguas. Por su parte, la formación profesional se vería apoyada con recursos como bibliotecas, colección de 
mapas, laboratorios y seis escuelas de ciencias aplicadas: artillería, ingeniería, canales, minería, puentes, caminos, ingeniería geográfica y construcción naval. El proyecto ofrecía grandes posibilidades; sin embargo, tenía un problema: carecía de fondos y no señalaba la manera de sostener $\tan$ ambicioso proyecto.

La situación económica del país impidió que estas iniciativas en materia educativa se pusieran en práctica; se dieron reajustes y, para 1827 , surge un tercer plan educativo, el cual busca nuevamente y con muy buenas intenciones impulsar la educación pública en el país; se precisa que todo ciudadano debe saber leer y escribir, además debe fortalecer la formación en urbanidad y civilidad; para ello se incluyen las materias de urbanidad y catecismo político; ambas materias estuvieron unidas de alguna manera al buscar como objetivo la formación de buenos ciudadanos que respetaran las reglas de la sociedad urbana; dichas materias compartieron espacios comunes prácticamente durante todo el siglo XIX. ${ }^{5}$

En su art. $2^{\circ}$ se indica que el número de escuelas se adaptará a la población de las parroquias; además se habla de un cuerpo de inspectores que deberá supervisar las escuelas. Los maestros serán examinados; se

${ }^{5} \mathrm{Al}$ respecto, ver los trabajos de Valentina Torres Septién y Jesús Marqués. fijan sueldos de $\$ 100.00$ para los maestros y $\$ 83.00$ para las maestras. $\mathrm{El}$ art. $13^{\circ}$ establece que la enseñanza es gratuita. ${ }^{6}$

Para 1832, durante la gestión de Anastasio de Bustamante, el Sr. Valentín Olaguíbel presentó ante la Cámara de Diputados un nuevo ensayo educativo, Proyecto sobre arreglo de la Instrucción Pública; en este documento se reconoce la difícil y penosa situación por la que atraviesa la instrucción pública en el país, la cual es el resultado de la inestable situación política y económica; de allí, que se plantee un plan sencillo y económico para la educación.

En su art. $1^{\circ}$ se anota: La enseñanza costeada por fondos públicos será pública, gratuita y uniforme.

Art. $2^{\circ}$. La enseñanza privada será libre, se impedirá que se enseñen doctrinas contrarias a la religión católica, la buena moral o contrarias a la Constitución. ${ }^{7}$

El currículo de primaria para niños incluye la materia de principios elementales de religión y de moral, y el de niñas incluye sólo materias propias de su sexo: lectura, escritura y aritmética; por supuesto, urbanidad y religión, y se suprime "Nociones de la Constitución". Para el nivel de preparatoria se eliminan once materias y sólo queda con cinco. Fi-

${ }^{6}$ Ernesto Meneses, op. cit.

${ }^{7}$ Ibid., p. 116. 
nalmente, en su art. $172^{\circ}$ se indican las funciones de la Dirección General de Instrucción Pública: velar por la enseñanza pública y cuidar que se observen los reglamentos.

Este proyecto efectivamente fue extremadamente sencillo, austero y conservador; tanto que al año siguiente es cancelado; en 1833 se desata la gran polémica en torno a la iniciativa liberal de educación laica; el vicepresidente Valentín Gómez Farías presentó una fuerte reforma educativa en la cual destacan los siguientes artículos: $1^{\circ}$. Se suprime la Universidad de México y se establece una Dirección General de Instrucción Pública para el Distrito Federal y los territorios de la federación, la cual tendrá a su cargo todos los establecimientos públicos de enseñanza; será la encargada de nombrar a los profesores de los ramos de enseñanza; así mismo será la encargada de elaborar los reglamentos y designará los libros elementales de enseñanza. Se indica que todos los gastos derivados de la instrucción pública serán pagados por el gobierno. Esta reforma da prioridad a la enseñanza primaria y normal, pues son espacios fundamentales para la formación de ciudadanos y para la formación de cuadros para la enseñanza.

Con esta reforma educativa el grupo liberal avanza, sus planteamientos están sobre la mesa: la libertad de enseñanza, la eliminación y distanciamiento de la Iglesia católica en temas educativos y la presencia del Estado como el único que debe asumir el control de la educación. Las ideas que nutren el pensamiento del cambio educativo están en el gran ideólogo José María Luis Mora, para el cual era indispensable establecer "una enseñanza absolutamente independiente del clero, enseñanza controlada por el Estado, enseñanza que trasmitiera el dogma liberal"; 8 sólo así se podría avanzar en la conformación de los nuevos ciudadanos que requería la nación, por supuesto, liberal.

El momento político no era el apropiado para impulsar una reforma educativa liberal; la reacción no tardó: el presidente Sana Anna no apoya la iniciativa; ante las fuertes críticas y reclamos, en 1834 derogó la reforma y prácticamente pidió disculpas a la sociedad conservadora del país; los ayuntamientos vuelven a ser los encargados de las escuelas de primeras letras.

Los cambios en materia educativa continúan y se presentan nuevas propuestas, aunque en esencia se mantienen las mismas premisas, unas defendidas por conservadores y otras por liberales. En 1842, se expedía un nuevo decreto que declaraba la educación obligatoria entre los 7 y los 15 años; además, debía ser

\footnotetext{
${ }^{8}$ Francios Xavier Guerra, op. cit., p. 396.
} 
gratuita. Se daba a la Compañía Lancasteria la Dirección General de Instrucción Primaria; con el cambio constitucional este ensayo fue derogado y para 1843 se redactó un nuevo ensayo educativo a cargo de Manuel Baranda y se anota "dar impulso a la instrucción pública, uniformarla y hacer efectiva su mejora y progresivos y firmes sus adelantos". 9

La situación del país para la década de los cuarenta era de caos, inestabilidad, crisis económica, intervenciones extranjeras, guerras, etc. y aún así, en medio de la total anarquía y de los constantes enfrentamientos entre liberales y conservadores, se presentaban y debatían nuevos proyectos educativos, muchos de ellos sumamente completos y ambiciosos.

Con el fin de la dictadura santanista, en el año de 1855, el país continúa en su intento por consolidar un proyecto de nación; sin embargo, aún está por definirse la línea política que tomara las "riendas del país".

\section{Los liberales y el proyecto educativo: vientos de cambio}

"A partir de la segunda mitad del siglo XIX los liberales concentraron sus esfuerzos en diseñar un proyecto

\footnotetext{
${ }^{9}$ Josefina Zoraida Vázquez, Nacionalismo y educación en México, 1979, México, El Colegio de México, p. 32.
}

educativo moderno bajo la dirección del Estado. La idea central era formar a los niños en la escuela, es decir, contar con una educación formal, la cual debía de atender de manera especial la formación cívica del niño". ${ }^{10}$ Siguiendo esta línea, François Xavier Guerra, señala que:

A través de la escuela se trasmiten los cimientos ideológicos de la enseñanza liberal: formar ciudadanos leales e industriosos. Es decir, individuos políticos nuevos, leales a la nación, que actúen como agentes económicos autónomos. ${ }^{11}$

Por tanto, todas las iniciativas estarán encaminadas a lograr dicho fin.

Los años que van de 1856 a 1867 constituyen un período de gran actividad en materia de legislación educativa. Juárez, a la cabeza de un destacado grupo de liberales, consideraba más que urgente pasar de las meras iniciativas a la normatividad en materia educativa; sin embargo, mucho de lo propuesto ya se había planteado anteriormente, pero ahora se daba fuerza a estas ideas al incluirlas en la Constitución de 1857. El tema educativo quedó incluido en el art. $3^{\circ}$ : "La enseñanza es libre; la ley deter-

\footnotetext{
${ }^{10}$ Rosalía Meníndez, "Nacionalismo y patriotismo, fundamentos para la formación de ciudadanos: los libros de texto de civismo para educación primaria, 1876-1921", en Las disciplinas escolares y sus libros, 2010, México, CIESAS, UAEM, Juan Pablos editores, p. 51-2.

${ }^{11}$ François Xavier Guerra, op. cit. p. 205.
} 
NOTAS

minará qué profesiones necesitan título para su ejercicio y con que requisitos se debe expedir". ${ }^{12}$

En 1856 se establece la secundaria para niñas, importante iniciativa que coloca la primera piedra en la construcción de la formación de las futuras maestras; para el año de 1857 se dan las bases para la fundación de escuelas normales.

Después de concluir la guerra de Tres Años, en 1861 se promulga $L a$ Ley de Instrucción Pública para el Distrito Federal y los Territorios Federales, la cual establece un nuevo plan de estudios para la educación primaria; los aspectos de orden cívico son considerados en la asignatura "Lectura y leyes fundamentales"; es evidente el interés de los liberales por dar a conocer la nueva legislación liberal entre los niños. En este mismo plan, las asignaturas "catecismo religioso" e "historia sagrada" son eliminadas definitivamente del currículo escolar por obvias razones como consecuencia de la separación de la Iglesia del Estado suscitado en el año 1859; en su lugar, se establece la materia de "moral", que se aboca a la enseñanza de los principios morales y que se mantendrá hasta finales del siglo XIX. ${ }^{13}$

${ }^{12}$ Josefina Vázquez, op. cit., p. 53.

${ }^{13} \mathrm{Al}$ respecto, ver Verónica Chavero Martínez, La enseñanza de la moral a través de los libros de texto para educación primaria, 1867-1908, Tesis de Maestría, 2010, México, Universidad Pedagógica Nacional, Ajusco.
La línea estaba trazada; como lo anota Josefina Vázquez: "había que arrancar la educación de las garras del clero y difundir ampliamente la enseñanza". La política educativa liberal avanza, y en 1867, se presenta La Ley Orgánica de Instrucción Pública, la cual señala que la instrucción pública es gratuita para los pobres y es obligatoria; la enseñanza religiosa desaparece totalmente, por lo menos en la legislación. Dos años más tarde se publica La Ley Reglamentaria de Instrucción Pública, que establece la creación de la Escuela Nacional Preparatoria, así como una serie de cambios en los planes del nivel primario y preparatorio.

El escenario educativo se había transformado, aunque básicamente en materia normativa; la realidad educativa aún estaba es espera del gran cambio; se requería de un presupuesto importante para transformar la precaria educación del país. Los esfuerzos fueron constantes y no se veía el desánimo entre los convencidos de las bondades de la educación. Ernesto Meneses señala que, desde 1823 hasta 1865 , se aplicaron ocho planes de estudio para primaria, en los cuales las asignaturas básicas eran: Lectura, Escritura, Aritmética y Catecismo Político; es decir, la enseñanza de materias básicas para la formación elemental, pero también algunas nociones de educación cívica; todo ello 
fue considerado por los políticos e interesados en promover un proyecto, programa o solo algunas líneas sobre la educación. Así, desde que México obtuvo su Independencia, el tema ha estado sobre la mesa.

Con la Restauración de la República en 1867, las asignaturas de Urbanidad y Moral tuvieron a su cargo la formación de valores en el niño; al mismo tiempo se incluyó Rudimentos de Geografía e Historia; la formación cívico-histórica del futuro ciudadano avanzaba sobre camino firme, los liberales contaban ya con la base normativa para la construcción del gran proyecto educativo liberal. Porfirio Díaz será el arquitecto de la modernidad educativa del México de entre siglos.

\section{La modernización y el proyecto educativo del Porfiriato}

El proyecto educativo del Porfiriato es uno: la modernización de la educación, con la idea de establecer un sistema educativo nacional, federal, uniforme, homogéneo, racional, laico y controlado única y exclusivamente por el Estado. ${ }^{14}$

\footnotetext{
${ }^{14} \mathrm{Al}$ respecto, ver Rosalía Meníndez Martínez, Modernidad y Educación Pública: Las escuelas primarias de la ciudad de México, 1876-1911", Tesis Doctoral, 2004, México, Universidad Iberoamericana.
}

Porfirio Díaz procuró, por diversos medios, transformar la sociedad que había recibido y convertirla en moderna, siguiendo para ello el ejemplo de los países avanzados; el orden y el progreso, premisas básicas del discurso positivista y del mundo industrial en ascenso, nutrieron el contenido de la modernidad. Para lograr este objetivo, resultaba necesario e indispensable contar con un Estado nuevo; en este sentido, el pensamiento positivista ofreció importantes elementos para su conceptualización: el orden sólo podía ser alcanzado por un Estado fuerte donde el presidente concentrara amplios poderes y ejerciera un control total sobre la sociedad; la libertad política sería sacrifica en aras de la evolución social. El trabajo del grupo en el poder se centró en consolidar un Estado poderoso que tuviera las posibilidades de impulsar y sostener un proyecto de nación; para ello, era necesario modificar las estructuras políticas y económicas vigentes. Para lograr tan ambicioso objetivo, había que transformar la sociedad y qué mejor manera que por medio de una educación moderna, libre, gratuita, obligatoria y uniforme.

La mayoría de los educadores y pedagogos de la época ${ }^{15}$ concebían

\footnotetext{
${ }^{15}$ Enrique C. Rébsamen,Luis E. Ruiz, Ezequiel Chávez, Justo Sierra, Enrique Laubscher, Gregorio Torres Quintero, Rosaura Zapata, Estefanía Castañeda, Miguel F. Martínez, Manuel Zayas Francisco Cosmes, entre muchos otros.
} 
NOTAS

la educación moderna como una educación racional, científica, objetiva, y laica; para llevar a cabo el proyecto modernizador resultaba indispensable que las escuelas fueran modernizadas en sus espacios, mobiliario, contenidos curriculares, libros de texto y maestros; aunado a esto, la educación debía lograr la uniformidad, homogeneidad y obligatoriedad en todo el país, pues sólo así se lograría una exitosa difusión del discurso liberal en todas las escuelas. El proyecto era claro, los actores estaban en el escenario: maestros, educadores, pedagogos, políticos, ministros y a la cabeza el presidente de la República, el General Porfirio Díaz; por primera vez, la educación tenía un rostro definido: la modernidad avalada y sostenida por el régimen porfirista.

Durante la gestión del Ministro don Joaquín Baranda (1880-1901), se logró conformar un proyecto educativo de corte nacional, con especial énfasis en la educación primaria y la formación de profesores; bajo su liderazgo, se obtuvieron importantes avances en materia de legislación educativa, ${ }^{16}$ pero sobre todo se logró

${ }^{16}$ En 1884 se promulgó el Reglamentó Interior para las Escuelas Nacionales Primarias; en 1887 se crea la Escuela Normal de Maestros; en 1888 se promulga La ley de Instrucción Primaria y se dan varias reformas al Plan de estudios de Educación Primaria; en este mismo año se promulgó La Ley de Enseñanza Obligatoria. la organización y realización de los Congresos de Instrucción Pública, celebrados en la ciudad de México durante los años de 1889-1890 y 1890-1891. La celebración de los Congresos educativos marcó un parteaguas en la educación del país; se puede decir que, a partir de ellos, la educación inició realmente un proceso de modernización en diversos ámbitos.

La segunda mitad de la década de los ochenta del siglo XIX representó un momento particularmente especial, pues durante estos años se esgrimieron una serie de leyes y reglamentos que dieron paso a la creación de un marco normativo para impulsar la modernización de la educación; bajo esta dinámica, la educación pública fue especialmente atendida, en particular el nivel primario, aunque también se realizaron importantes avances para normar la educación privada. ${ }^{17}$ La élite educativa que rodeaba al General Díaz buscaba generar nuevos enfoques educativos con miras a establecer una educación vinculada con el proceso de industrialización que se imponía en el mundo; además, intentaba formar nuevas generaciones de ciudadanos trabajadores, sanos y disciplinados.

${ }^{17} \mathrm{Al}$ respecto ver el trabajo de Valentina Torres Septién, La educación privada en México, 1903-1906, 1996, México, El Colegio de MéxicoUniversidad Iberoamericana. 
La vida escolar fue trastocada por los vientos modernizadores; se dio énfasis a la reformulación de los planes y programas de estudio, que dieron pie a la conformación de un currículo renovado; el establecimiento de métodos de vanguardia, retomados de experiencias norteamericanas; la puesta en práctica de actividades que enfatizaban la parte racional, científica, cívica y práctica de la enseñanza; todo ello formaba parte de un ideal de formación moderna. Los libros de texto no quedaron al margen de estas transformaciones; muy por el contrario, fueron objeto de atención especial por parte de las autoridades educativas, de los pedagogos y de los maestros. Cada disciplina fue diseñando sus propios libros de texto, elaborados de acuerdo con la normatividad establecida, ya que de no ser así, no tendrían posibilidad de ser aceptado en las escuelas. A partir de 1885, la Escuela Normal de Maestros se encargó de seleccionar los textos para el ciclo escolar correspondiente.

La preparación cívica e histórica de los niños fue particularmente cuidada por el Estado liberal; para su enseñanza se contó con programas y libros escolares especialmente diseñados para tal fin; para 1887, el currículo de primaria incluía una materia nueva: "Instrucción Moral y Cívica”; al respecto, Justo Sierra anota: "en las escuelas primarias de todos los ámbitos de la nación se formará no sólo al hombre socialmente hablando sino al ciudadano mexicano, inspirado en los grandes ideales que la patria persigue". ${ }^{18}$ Todos los planes de estudio posteriores incluyeron e incluyen la materia de civismo.

La década de los ochenta fue particularmente fructífera en materia educativa, pues en este período se organizaron dos importantes y fundamentales congresos: el Higiénico Pedagógico (1882) y el de Instrucción Pública (1889-1890), que incidieron en la reorganización de la educación primaria en el país; marcaron el inicio de una serie de reformas que condujeron a la educación pública a tomar nuevos caminos.

Para 1888, se publicó la Ley de Instrucción Pública; las materias consideradas como básicas en esta Ley incluían la: "instrucción moral y cívica, la lengua nacional, la lectura y escritura, las nociones de cálculo aritmético y geometría, los elementos de ciencias fundamentales de observación y experimentación, datos elementales de geografía y nociones de historia natural, dibujo, canto coral, manejo de los útiles de los oficios mecánicos, ejercicios gimnásticos, ejercicios militares (para niños) y labores manuales (para niñas)". ${ }^{19}$ Todas

${ }^{18}$ Ernesto Meneses, op. cit., p. 447.

${ }^{19}$ Ibid., p. 429. 
NOTAS

estas materias estaban encaminadas a fortalecer la formación cívica y científica de los alumnos e implicaron modificaciones en la estructura del currículo.

A su vez, esta legislación enfatizó el carácter de obligatoriedad de la enseñanza elemental en el Distrito Federal y Territorios, para varones y mujeres de 6 a 12 años; ${ }^{20}$ de fondo estaba nuevamente el plan para impulsar una educación unitaria, que ofreciera los mismos conocimientos en todas las escuelas públicas; al ser obligatoria la enseñanza, el discurso liberal podía fluir más fácilmente.

La década de los noventa resultó particularmente prolífica para la educación; se dieron importantes medidas que fortalecieron el aparato educativo a cargo del Estado, el cual tuvo cada vez mayores facultades para dirigir la enseñanza pública. La legislación hacía énfasis en los programas y en los métodos. Al respecto, la Ley Reglamentaria de 1896 indicaba en el art. $66^{\circ}$ : se establece una Dirección General de Instrucción Primaria, á fin de que ésta se difunda $\mathrm{y}$ atienda con uniformidad, bajo un mismo plan científico y administrativo. ${ }^{21}$ Cada materia contaba con su

${ }^{20}$ Ley de Instrucción Pública, mayo 23, 1888.

21 "Ley Reglamentaria de la Instrucción Obligatoria en el Distrito Federal y en los Territorios de Tepic y de la Baja California", en Revista de Instrucción Pública Mexicana, t. I. núm. 9, julio 15, 1896, p. 257. respectivo programa, que detallaba por año escolar las actividades y contenidos que debían tratarse por grado; el profesor contaba con una guía para la enseñanza de los aspectos fundamentales del programa de estudios, pero, sobre todo, con los lineamientos para que impartiera solamente lo estipulado por la autoridad.

En 1908 se promulgó la Ley de Educación Primaria, que si bien era para el Distrito Federal y Territorios, fue acogida en breve tiempo por todo el país. Este documento expresa los intereses del equipo diseñador de la política educativa ${ }^{22} \mathrm{y}$, en particular, la visión de Justo Sierra, responsable de la educación del país; se destacaban los aspectos prioritarios de esta política, que se resumían en tres: el aspecto moral y cívico, que ahora adquiría tintes modernos, acordes con el proyecto de industrialización que invadía al mundo occidental y que requería de la formación de ciudadanos obedientes y disciplinados; y los aspectos científico y físico.

La política educativa del régimen porfirista se sustentó no sólo en legislación, sino que, por primera vez en todo el siglo XIX, se pasó de las buenas intenciones a las acciones concretas;

${ }^{22}$ Nos referimos a Justo Sierra, Ezequiel Chávez, Enrique Laubscher, Enrique C. Rébsamen, Joaquín Baranda, Justino Fernández, Luis E. Ruiz, Gregorio Torres Quintero, Julio S. Hernández, Abraham Castellanos, Estefanía Castañeda, Rosaura Zapata. 
un presupuesto y un espacio político administrativo propio le dieron la fuerza para poder esgrimir un fuerte proyecto modernizador, por supuesto, éste contó con el aval político de Porfirio Díaz y con la inteligencia, compromiso e iniciativas de maestros, pedagogos y educadores mexicanos y algunos de ellos extranjeros, que ofrecieron grandes aportaciones a la educación mexicana; destacan: Enrrique C. Rébsamen, E. Laubcher y Leopoldo Kiel entre otros. Todo ello se conjuntó para la transformación educativa.

\section{Consideraciones finales}

El siglo XIX da cuenta de una ardua labor de hombres interesados en la construcción de una nación imaginada. Se buscan las ideas de intelectuales, políticos, maestros, militares $\mathrm{y}$ en general hombres con ideales a veces un tanto románticos para transformar un país tan desigual; sin embargo, el propio avanzar del siglo con sus duras sacudidas tranformó sus ideas, ahora pragmáticas y racionales, hasta llegar a mirar a la modernidad como el paradigma de la nación mexicana. El caos, la inestabilidad política y económica no fueron limitantes para construir un proyecto educativo; el desánimo no era parte del siglo, muestra de ello es la cantidad de documentación escrita a lo largo de estos años: leyes, decretos, constituciones, reglamentos, manuales, libros, y mucho más. El objetivo era claro: se requería de la educación para construir y dar sentido a la nación.

Tanto los liberales como los conservadores mantuvieron una línea de unión, a pesar de sus diferencias ideológicas: la educación obligatoria y gratuita; para los primeros, laica; para los segundos, religiosa; claro que los caminos se bifurcaron y finalmente el pensamiento liberal se plasmó en el proyecto educativo del porfiriato, el único que logró esgrimir un fuerte proyecto de modernización para la educación pública y, con ello, sentar la base del sistema educativo nacional del siglo XX. Los resultados no estuvieron en la cantidad, sino en la calidad del proyecto y en el impacto que éste tuvo en la formación educativa de los niños y jóvenes mexicanos del período de entre siglos. 
La reproducción total o parcial de este artículo se podrá hacer si el ITAM otorga la autorización previamente por escrito. 